\title{
WWOX gene is associated with HDL cholesterol and triglyceride levels
}

\author{
María E Sáez ${ }^{1 *}$, Antonio González-Pérez', María T Martínez-Larrad², Javier Gayán', Luis M Real', \\ Manuel Serrano-Ríos ${ }^{2}$, Agustín Ruiz ${ }^{1}$
}

\begin{abstract}
Background: Altered lipid profile, and in particular low HDL and high triglyceride (TG) plasma levels, are within the major determinants of cardiovascular diseases. The identification of quantitative trait loci (QTL) affecting these lipid levels is a relevant issue for predictive purposes. The WWOX gene has been recently associated with HDL levels. This gene is located at chromosome $16 \mathrm{q} 23$, a region previously linked to familial combined hyperlipidemia (FCHL) and HDL. Our objective is to perform a genetic association analysis at the WWOX gene region with HDL, TG and TG/HDL ratio.
\end{abstract}

Methods: A quantitative association analysis performed in 801 individuals selected from the Spanish general population.

Results: For HDL levels, two regions of intron 8 display clustering of positive signals $(p<0.05)$ but none of them was associated in the haplotypic analysis $(0.07 \leq p \leq 0.165)$. For TG levels not only intron 8 but also a $27 \mathrm{~kb}$ region spanning from the promoter region to intron 4 are associated in this study. For the TG/HDL genetic association analysis, positive signals are coincident with those of the isolated traits. Interestingly, haplotypic analysis at the $5^{\prime}$ region showed that variation in this region modified both HDL and TG levels, especially the latter $(p=0.003)$.

Conclusions: Our results suggest that WWOX is a QTL for both TG and HDL.

\section{Background}

Altered lipid profile is one of the major determinants of cardiovascular disease, which is the first cause of death in the developed countries. Unhealthy diet and low physical activity both contribute to the appearance of dyslipidemia, but blood lipid profile is also highly heritable. In addition to several mendelian forms of hyperlipemia and hypertriglyceridemia, dyslipidemia is commonly a complex disease or group of diseases with an estimated heritability ranging from 25 to $80 \%$ [1]. A recent study performed in 1,275 coronary artery disease patients derived from the Regensburg Myocardial Infarction Family Study has described heritabilities of $27-48 \%$ for HDL cholesterol and 21-44\% for LDL cholesterol [2].

The genetic variation in genes such as lipoprotein lipase (LPL), hepatic lipase (LIPC), the LDL receptor (LDLR), the $\mathrm{ABCA} 1$ transporter or diverse apolipoproteins, has

\footnotetext{
* Correspondence: mesaez@neocodex.es

'Departamento de Genómica Estructural. Neocodex. C/. Charles Darwin 6,

Acc. A, 41092 Sevilla, Spain

Full list of author information is available at the end of the article
}

been found to influence blood lipid levels [3-8]. Lately, the rapid spread of genome-wide association studies has allowed not only the confirmation of previously described associations, but also the identification of many quantitative trait loci (QTL) for lipid levels across the genome [9-15]. One of these loci has been recently reported for HDL [16] and involves the WW-domain-containing oxidoreductase (WWOX) gene (MIM 605131). WWOX gene is a large gene spanning about $1.1 \mathrm{Mb}$ and located within a region previously linked to HDL and familial combined hyperlipidemia (FCHL), a hereditary disorder characterized by the elevation of both cholesterol and triglycerides (TGs) in the blood [17-21]. WWOX encodes a protein which contains 2 WW domains and a short-chain dehydrogenase/reductase domain (SRD). The highest normal expression of this gene is detected in hormonally regulated tissues such as testis, ovary, and prostate [22]. This expression pattern and the presence of an SRD domain suggest a role for this gene in steroid metabolism. In fact, WWOX is implicated in tumorigenesis [23-25], a pathological process highly dependent on cholesterol metabolism. In fact, 
WWOX knockout mouse model exhibits hypotriglyceridemia and hypocholesterolemia among other metabolic disturbances [26]. A recent report by Vasan et al. [27] associated the rs 2059238 polymorphism, located at intron 5 , with left ventricular wall thickness in individuals with coronary artery disease (CAD).

To assess the effect of this gene in our population, we have analysed the $W W O X$ gene region for association with TGs, HDL and TG/HDL ratio. The TG and HDL levels are inversely correlated and their metabolism are closely interrelated. Therefore, the TG/HDL ratio has been suggested to be a powerful estimator of cardiovascular disease risk $[20,28]$. We have analysed for association with HDL, TG and TG/HDL, 1045 polymorphisms genotyped from the Affymetrix $250 \mathrm{k} \mathrm{NspI}$ assay or imputed with MACH 1 software using CEU HapMap phased haplotype data [29].

\section{Methods}

\section{Study design}

This study comprises 801 non related Caucasian men $(\mathrm{n}=433,54.05 \%)$ and women $(\mathrm{n}=368,45.95 \%)$ who were recruited by a simple random sampling approach from a cross-sectional population-based epidemiological survey in Spain, aimed at investigating the prevalence of anthropometric and physiological parameters related to obesity and other components of MS [30,31]. Participants with previous diagnosis of type 1 diabetes were excluded from the study.

All participants gave their written consent to participate in the study. The study protocol was approved by the Ethics Committee of the Hospital Clínico San Carlos of Madrid.

\section{Measurements \\ Biochemical determinations}

After an overnight fasting period, $20 \mathrm{ml}$ of blood were obtained from an antecubital vein without compression. HDL and TG levels were determined by enzymatic methods using commercial kits from Boehringer Mannheim.

\section{Genotypes}

Genotypic data were derived from a genome wide scan performed with the $250 \mathrm{k}$ NspI Affymetrix chip. Genotyping was done according to manufacturer's instructions.

\section{Genetic quality control}

Of the 253 polymorphism included in the Affymetrix chip located at the WWOX genomic region (transcribed region $\pm 2 \mathrm{~kb}$ ), only 175 passed the quality control filtering (at least $90 \%$ of individuals genotyped, minor allele frequency (MAF) $\geq 0.05$, and Hardy-Weinberg equilibrium $\mathrm{p}>0.05)$.

\section{Statistical analysis}

To compare our results with those previously published, the 175 genotyped SNPs were used to impute untyped polymorphism in the region using $\mathrm{MACH} 1$ software (http://www.sph.umich.edu/csg/abecasis/MACH) [29] and CEU HapMap phased haplotypic data (http://www. HapMap.org), since no significant differences were observed between the Spanish and the HapMap populations (Additional files 1-2). According to the software recommendations, only those SNPs with a $\mathrm{r}^{2}>0.30$ were selected for the association analysis (870 polymorphisms). Quality metrics for imputed genotypes are included in Additional file 3. Finally, 1045 SNPs (151 directly genotyped and 894 imputed, all of them with MAF $\geq 0.10$ ) were analysed for association with HDL, TGs and HDL/ TG ratio using the linear regression procedure included in the PLINK software [32]. 39 individuals under lipid lowering medications were excluded from the genetic association analyses. All the studies were adjusted by sex, age, BMI, smoking (defined as present or past history of smoking of at least five cigarettes per day for a minimum of 5 years), alcohol consumption (defined as a daily intake of more than 1 drink, equivalent to $10 \mathrm{~g}$ of pure ethanol), and physical activity (physical activity was defined as light or moderate activity for a minimum of 60 minutes per session at least three times a week). Empirical $p$ values were obtained using the adaptative permutation method implemented in PLINK [32]. We have not applied multiple comparison correction because we consider it over-conservative for the replication of a previously described gene specially given that most genotypes analysed in this report are derived from a small number of observed genotypes; a $\mathrm{p}$ value under 0.05 is interpreted as significant.

Linkage disequilibrium (LD) patterns at the WWOX gene were analysed using Haploview software [33].

For haplotypic association analysis, we have also employed PLINK v1.06 software [32]. Only haplotypes with a population frequency over $5 \%$ were retained for analysis.

\section{Results}

The characteristics of the study population are described in Table 1.

For all the traits analysed, we have identified four regions displaying clustering of positive signals (Additional files $4,5,6,7)$. They have been numbered on the basis of their chromosomal positions from 5' to 3' (Figure 1): region 1 from 76,689,775 to 76,716,533 bp (NCBI36/ hg18), region 2 from $77,433,428$ to $77,441,867$ bp (NCBI36/hg18), region 3 from 77,538,855 to 77,563,088 bp (NCBI36/hg18), and region 4 from $77,605,536$ to $77,620,657$ bp (NCBI36/hg18). The complete list of the 
Table 1 Characteristics of the study population

\begin{tabular}{lllll}
\hline & $\begin{array}{l}\text { All } \\
\boldsymbol{N}=\mathbf{8 0 1}\end{array}$ & $\begin{array}{l}\text { Men } \\
\boldsymbol{N}=\mathbf{4 3 3}\end{array}$ & $\begin{array}{l}\text { Women } \\
\boldsymbol{N}=\mathbf{3 6 8}\end{array}$ & $\begin{array}{l}\text { Men vs women } \\
\boldsymbol{P} \text { value }\end{array}$ \\
\hline Age (years) & $51.90(8.81)$ & $51.57(9.24)$ & $52.30(8.28)$ & 0.242 \\
\hline BMI $(\mathbf{k g} / \mathbf{m} \mathbf{)})$ & $27.44(4.29)$ & $27.11(3.71)$ & $27.84(4.87)$ & 0.017 \\
\hline Triglycerides (mg/dl) & $104.81(73.23)$ & $116.36(83.38)$ & $91.21(56.26)$ & $1.09 \times 10^{-6}$ \\
\hline HDL $(\mathbf{m g} / \mathbf{d l})$ & $50.57(20.78)$ & $46.08(19.09)$ & $55.86(21.45)$ & $1.72 \times 10^{-11}$ \\
\hline Smokers (\%) & $28.6 \%$ & $42.5 \%$ & $12.2 \%$ & $1.34 \times 10^{-14}$ \\
\hline Alcohol consumers (\%) & $66.0 \%$ & $83.4 \%$ & $45.7 \%$ & $2.97 \times 10^{-14}$ \\
\hline Physical active (\%) & $46.3 \%$ & $45.3 \%$ & $47.6 \%$ & 0.523 \\
\hline
\end{tabular}

For quantitative traits, values represent means and, in brackets, standard deviations (SD). For the statistical differences $p$ values (Anova test for quantitative traits and exact test for dichotomic traits) are given.

results from the association analysis can be accessed online (Additional files 8, 9, 10).

For HDL levels, two regions concentrate the positive signals, both of them in the WWOX gene intron 8 (Figure 1A and Additional file 8). The first of them, comprises linked SNPs in the region 77,433,428 - 77,441,867 bp (rs7405423rs4145518, region 2); the adjacent LD block $(77,442,683$ 77,457,346 bp, rs8060856-rs2656634), partially linked with it ( $\mathrm{D}^{\prime}=0.92$, Additional file 5), also shows associated markers. The strongest associations in the region were observed for the rs4888865 ( $\mathrm{p}=0.006, \beta=0.96)$ and the rs4145518 ( $\mathrm{p}=0.007, \beta=1.03$ ) polymorphisms. The second associated region, also in the $8^{\text {th }}$ intron, is distal to the previous one $(77,538,855-77,563,088 \mathrm{bp}$, region 3$)$ and comprises a large LD block of 42 markers (rs11643794rs1110894, Additional file 6) of which the rs2047927 showed the highest significance $(\mathrm{p}=0.003, \beta=-2.25)$.

For TG quantitative association analysis, again two regions in the intron 8 showed clustering of positive signals (Figure $1 \mathrm{~b}$ and Additional file 9). One of these regions was the same LD block at the region 77,433,428 $77,441,867$ bp associated with HDL (region 2), but the signal was limited in this case to the seven first highly linked markers (rs7405423-rs7501409, D' $=1$ ). The other associated region in intron 8 extends from 77,605,536 to $77,620,657$ bp (rs12598471-rs2550698, region 4, Additional file 7), showing a peak at the rs11645630 $(\mathrm{p}=0.002, \beta=-11.14)$. However, the highest signals in this study are located at 76,689,775-76,716,533 bp (rs10220974-rs1076514, region 1, Additional file 4), a broad region that extends from the promoter to the $4^{\text {th }}$ intron, with the largest association at rs11645006 $(\mathrm{p}=0.0002, \beta=-13.81)$.

In the association study of the TG/HDL index, regions 1 (from $76,689,775$ to $76,716,533 \mathrm{bp}$, promoter region) and 2 (intron 8, from 77,433,428 to 77,441,867 bp) huddle associated SNPs (Figure $1 \mathrm{C}$ and Additional file 10). For the region 1, that is associated with TGs but not with HDL, $p$ values are smaller than those obtained for TGs. On the other hand, in the region 2, which is associated with both HDL and TGs, the significance is increased with respect to the individual phenotypes. Additionally, four markers of those included in region 4 (intron 8, from 77,605,536 to 77,620,657 bp) exceed the $0.05 \mathrm{p}$ value threshold.

\section{Haplotypic analysis}

We have also performed a haplotypic association analysis in the regions associated in the genotypic study (Table 2). The global haplotypic effect at region 1 $(76,689,775-76,716,533 \mathrm{bp})$ was significant for all the traits analysed $(0.0029 \leq \mathrm{p} \leq 0.0180)$, despite that allelic analysis did not show any associated marker with HDL. For region $2(77,433,428$ - 77,441,867 bp), only HDL was not significant. For regions 3 (77,538,855-77,563,088 bp) and $4(77,605,536-77,620,657 \mathrm{bp})$, only the analysis of TGs at region 4 was significant. Selection of tag SNPs did not improve the results of the association analysis (data not shown).

\section{Discussion}

We have reported association of four WWOX gene regions with HDL and TG levels. One of them is located at the 5' end of the gene, from the promoter to the intron 4 (region 1) whereas the remaining regions are placed at the intron 8 of the gene, a region previously associated with HDL levels by Lee et a. [16]. Haplotypic analysis pointed out that the allelic combinations at region 1 significantly modify HDL, TG levels and the TG/HDL index, despite that no individual SNP associations were found for HDL in this region. Moreover, none of the intron 8 regions are associated with HDL in the haplotypic analysis, although region 2 shows a trend for association ( $\mathrm{p}=0.07)$. Regions 2 and 4 are associated with TG levels and only region 2 with the TG/HDL index.

Our results suggest that the WWOX gene is associated with HDL and TGs levels in our study population. From a functional point of view, the 5' region of the gene with both TG and HDL is highly interesting, since includes regulatory regions of the gene and two $44 \mathrm{bp}$ insertion/ 


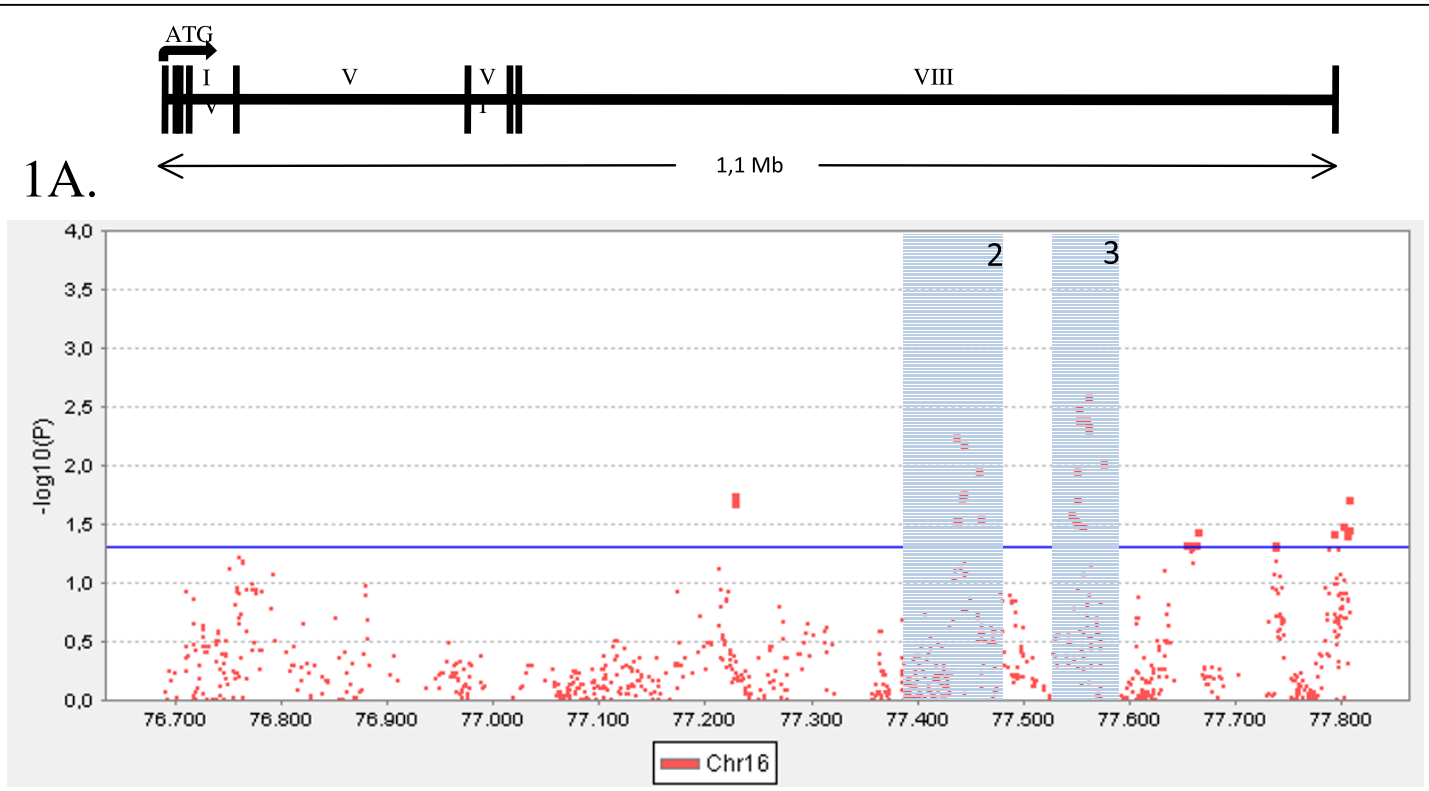

$1 \mathrm{~B}$.

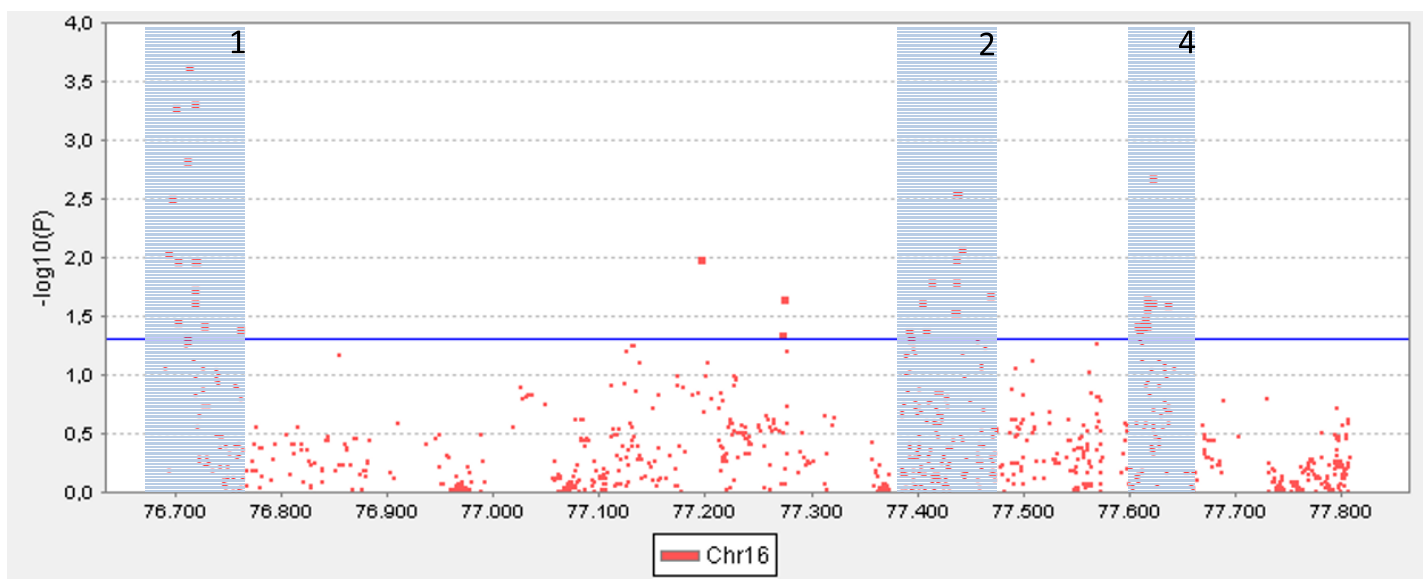

$1 \mathrm{C}$.

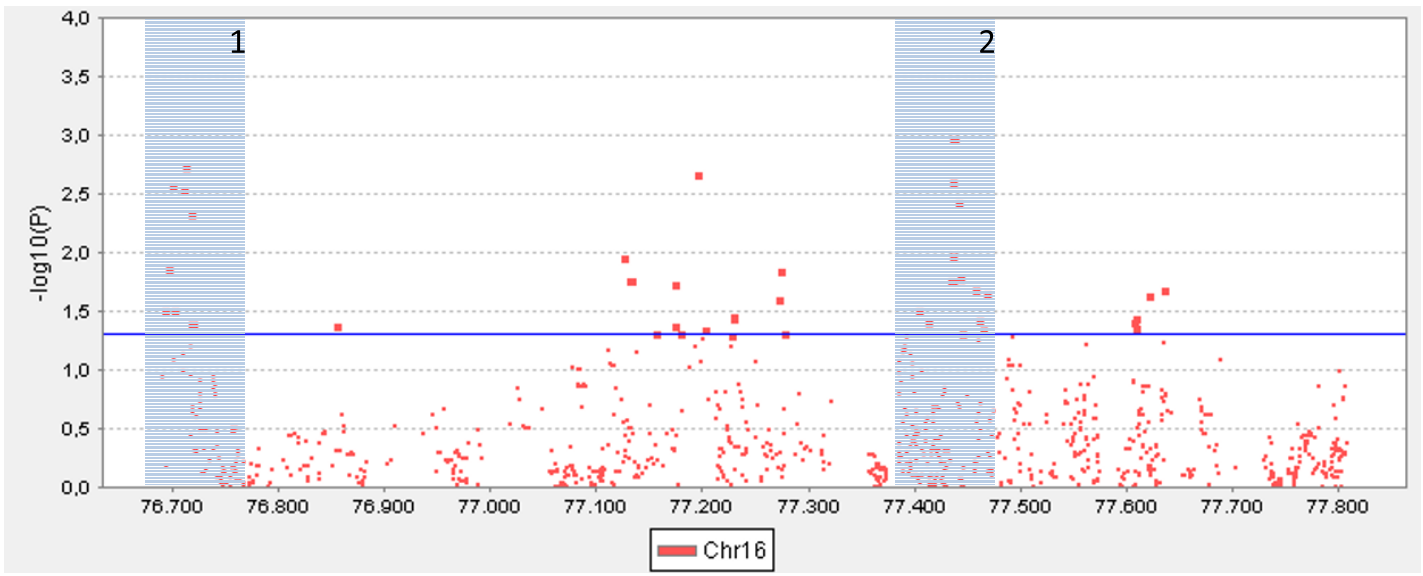

Figure 1 Graphical representation of the association analysis of the WWOX gene with HDL (Figure 1A), triglycerides (Figure 1B) and TG/HDL index (Figure 1C). Dots symbolize the logarithm of the $p$ value at each marker. In the top of the Figure a scaled representation of the WWOX gene structure is shown. Shaded numbered zones point out the regions referred in the text as regions 1-4. 
Table 2 Haplotypic analysis at the four WWOX regions selected in the genotypic analysis

\begin{tabular}{|c|c|c|c|c|c|}
\hline & HAPLOTYPE & FREQ. & TGs & HDL & TGs/HDL \\
\hline \multirow[t]{9}{*}{ REGION 1} & CTTCCTCCCGCGCAGA & 0.14 & (-ref) & (-ref) & (-ref) \\
\hline & TTCGATCTTCGATGGG & 0.12 & $\begin{array}{l}11.44 \\
(0.09 ; 22.80)\end{array}$ & $\begin{array}{l}0.38 \\
(-2.03 ; 2.78)\end{array}$ & $\begin{array}{l}0.28 \\
(-0.05 ; 0.59)\end{array}$ \\
\hline & CCTGAGTTTCGACAGG & 0.11 & $\begin{array}{l}10.05 \\
(-1.96 ; 22.10)\end{array}$ & $\begin{array}{l}-2.14 \\
(-4.68 ; 0.41) \\
\end{array}$ & $\begin{array}{l}0.34 \\
(0.01 ; 0.68) \\
\end{array}$ \\
\hline & CCTGAGTTTCGATGGG & 0.17 & $\begin{array}{l}15.32 \\
(5.27 ; 25.40)\end{array}$ & $\begin{array}{l}0.41 \\
(-1.72 ; 2.54)\end{array}$ & $\begin{array}{l}0.39 \\
(0.10 ; 0.67)\end{array}$ \\
\hline & CTCGATTITCCGCACA & 0.09 & $\begin{array}{l}2.85 \\
(-10.30 ; 16.00)\end{array}$ & $\begin{array}{l}0.60 \\
(-2.18 ; 3.38)\end{array}$ & $\begin{array}{l}0.003 \\
(-0.37 ; 0.38)\end{array}$ \\
\hline & CCTGAGTTTCCACAGG & 0.07 & $\begin{array}{l}7.82 \\
(-6.54 ; 22.20)\end{array}$ & $\begin{array}{l}4.24 \\
(1.2 ; 7.28)\end{array}$ & $\begin{array}{l}0.03 \\
(-0.38 ; 0.43)\end{array}$ \\
\hline & СTTCCTCTTCCATAGG & 0.05 & $\begin{array}{l}10.54 \\
(-5.77 ; 27.00)\end{array}$ & $\begin{array}{l}2.73 \\
(-0.75 ; 6.19)\end{array}$ & $\begin{array}{l}0.23 \\
(-0.23 ; 0.69)\end{array}$ \\
\hline & CTTCCTCTTCCGCACA & 0.07 & $\begin{array}{l}-15.76 \\
(-30.20 ;-1.29)\end{array}$ & $\begin{array}{l}2.04 \\
(-1.02 ; 5.11)\end{array}$ & $\begin{array}{l}-0.42 \\
(-0.83 ;-0.01)\end{array}$ \\
\hline & GLOBAL HAPLOTYPIC EFFECT & & $\begin{array}{l}F=3.13 \\
p=\mathbf{0 . 0 0 3}\end{array}$ & $\begin{array}{l}F=2.435 \\
p=\mathbf{0 . 0 1 8}\end{array}$ & $\begin{array}{l}F=2.836 \\
p=\mathbf{0 . 0 0 6}\end{array}$ \\
\hline \multirow[t]{6}{*}{ REGION 2} & TGACAAGACATG & 0.09 & (-ref) & (-ref) & (-ref) \\
\hline & CATAAAGAGGTA & 0.07 & $\begin{array}{l}1.50 \\
(-13.50 ; 16.50)\end{array}$ & $\begin{array}{l}-2.62 \\
(-5.79 ; 0.56)\end{array}$ & $\begin{array}{l}0.09 \\
(-0.33 ; 0.52)\end{array}$ \\
\hline & CATACGCGGGTA & 0.52 & $\begin{array}{l}12.54 \\
(3.34 ; 21.70)\end{array}$ & $\begin{array}{l}-2.43 \\
(-4.37 ;-0.48)\end{array}$ & $\begin{array}{l}0.41 \\
(0.15 ; 0.66)\end{array}$ \\
\hline & CATACGCGGGCA & 0.19 & $\begin{array}{l}8.36 \\
(-2.86 ; 19.60)\end{array}$ & $\begin{array}{l}-3.33 \\
(-5.7 ;-0.95)\end{array}$ & $\begin{array}{l}0.31 \\
(-0.01 ; 0.62)\end{array}$ \\
\hline & CATACGCGCATA & 0.05 & $\begin{array}{l}20.08 \\
(3.23 ; 36.90)\end{array}$ & $\begin{array}{l}-1.81 \\
(-5.37 ; 1.76)\end{array}$ & $\begin{array}{l}0.67 \\
(0.20 ; 1.15)\end{array}$ \\
\hline & GLOBAL HAPLOTYPIC EFFECT & & $\begin{array}{l}F=2.72 \\
p=\mathbf{0 . 0 2 8}\end{array}$ & $\begin{array}{l}F=2.17 \\
p=0.070\end{array}$ & $\begin{array}{l}F=3.50 \\
p=\mathbf{0 . 0 0 7}\end{array}$ \\
\hline \multirow[t]{4}{*}{ REGION 3} & GACGCTGCACTAGCGATCATTAGTACCAGACATGACAGCCCGC & 0.28 & (-ref) & (-ref) & (-ref) \\
\hline & ATGTTCAGAGTAAGCGAGGTCACCGCGGCGGCCAGGGATATAT & 0.31 & $\begin{array}{l}3.62 \\
(-11.30 ; 4.04)\end{array}$ & $\begin{array}{l}0.72 \\
(-0.89 ; 2.34)\end{array}$ & $\begin{array}{l}-0.13 \\
(-0.34 ; 0.09)\end{array}$ \\
\hline & GAGGTTGGGCAGGCCATCACTGCTACCAGACCTGAGAACACAC & 0.07 & $\begin{array}{l}-12.22 \\
(-25.10 ; 0.67) \\
\end{array}$ & $\begin{array}{l}-2.07 \\
(-4.78 ; 0.65)\end{array}$ & $\begin{array}{l}-0.26 \\
(-0.62 ; 0.11)\end{array}$ \\
\hline & GLOBAL HAPLOTYPIC EFFECT & & $\begin{array}{l}F=1.89 \\
p=0.151\end{array}$ & $\begin{array}{l}F=1.81 \\
p=0.165\end{array}$ & $\begin{array}{l}F=1.35 \\
p=0.261\end{array}$ \\
\hline \multirow[t]{6}{*}{ REGION 4} & GCTCTCCCGAAGGCCAGAGAACACCTAGACGATT & 0.12 & (-ref) & (-ref) & (-ref) \\
\hline & GCTCTCCCTAGGGTAGAAAGCATTCCCCAAGATT & 0.06 & $\begin{array}{l}-11.44 \\
(-27.80 ; 4.88)\end{array}$ & $\begin{array}{l}0.54 \\
(-2.93 ; 4.02)\end{array}$ & $\begin{array}{l}-0.32 \\
(-0.79 ; 0.14)\end{array}$ \\
\hline & $\overline{\text { GTACGAGCGAAGGCCAGAGAACACCTAGACGATT }}$ & 0.18 & $\begin{array}{l}6.45 \\
(-3.59 ; 16.50)\end{array}$ & $\begin{array}{l}-1.09 \\
(-3.24 ; 1.04)\end{array}$ & $\begin{array}{l}0.20 \\
(-0.09 ; 0.48)\end{array}$ \\
\hline & GTACGAGCTAGGGTAGAAAGCATTCCCCAAGATT & 0.18 & $\begin{array}{l}-6.28 \\
(-15.4 ; 2.84)\end{array}$ & $\begin{array}{l}-0.30 \\
(-2.24 ; 1.64)\end{array}$ & $\begin{array}{l}-0.09 \\
(-0.35 ; 0.17)\end{array}$ \\
\hline & $\overline{\text { GTACGAGCGGGAACCGGGAAACACCCACACAATT }}$ & 0.07 & $\begin{array}{l}11.58 \\
(-1.97 ; 25.10)\end{array}$ & $\begin{array}{l}-1.02 \\
(-3.90 ; 1.87)\end{array}$ & $\begin{array}{l}0.28 \\
(-0.11 ; 0.66)\end{array}$ \\
\hline & GLOBAL HAPLOTYPIC EFFECT & & $\begin{array}{l}F=2.61 \\
p=\mathbf{0 . 0 3 4 7}\end{array}$ & $\begin{array}{l}F=0.43 \\
p=0.786\end{array}$ & $\begin{array}{l}F=1.99 \\
p=0.0939\end{array}$ \\
\hline
\end{tabular}

Region 1 (Chr.16: 76,689,775-76,716,533 bp): rs10220947, rs4887935, rs7192129, rs12931172, rs8045450, rs2287973, rs2287972, rs16947127, rs16947129, rs12917833, rs10492874, rs11645006, rs2042356, rs1079569, rs12920698, rs1076514.

Region 2 (Chr.16: 77,433,428 - 77,441,867 bp): rs7405423, rs7405283, rs9922613, rs48888665, rs6420411, rs1543296, rs7498176, rs7501409, rs12447303, rs7190122, rs11643930, rs4145518.

Region 3 (Chr.16: 77,538,855-77,563,088 bp): rs11643794, rs11642227, rs10871357, rs4888887, rs1995549, rs8063186, rs11648482, rs7205567, rs16949032, rs17709129, rs17709147, rs17635945, rs11150119, rs9319530, rs13334115, rs10871358, rs12596756, rs12925319, rs 16949036, rs12447067, rs9941223, rs7189021, rs17636170, rs8052880, rs4600477, rs4888888, rs4888889, rs8052893, rs11150120, rs13339083, rs48888892, rs13330742, rs 16944152, rs2047927, rs5024396, rs17636262, rs2062900, rs8057659, rs12716865, rs1467067, rs11860206, rs1110891, rs1110894.

Region 4 (Chr.16: 77,605,536 - 77,620,657 bp): rs12598471, rs2550725, rs1862841, rs16949214, rs2550724, rs12447246, rs2550723, rs 16949222, rs2113305, rs7185820, rs8064141, rs 16949238, rs16949240, rs2656653, rs2550718, rs2550717, rs2550716, rs 16949251, rs8047597, rs2550711, rs8047300, rs2550710, rs7199119, rs1808447, rs905781, rs8053936, rs2550702, rs2550701, rs2656649, rs11645630, rs16949276, rs2656647, rs2656646, rs2550698. 
deletion polymorphisms. For the $W W O X$ gene, there have been eight different mRNAs described (7 alternatively spliced variants and 1 unspliced form) and three probable alternative promoters [34]. Of eight transcripts, six spliced and the unspliced mRNAs putatively encode good proteins. It is tempting to speculate that genetic variations in this region could modify the expression of the $W W O X$ gene. Functional analyses are needed to answer this hypothesis.

The second region identified in this study is, of the three regions identified in intron 8 , the one nearest to the 5 ' boundary of this uncoding region. It is associated with all the traits analysed, although for HDL, it didn't reach the statistical significance threshold. This region is in high LD with the rs2548861 polymorphism associated by Lee et al. ( $\left.D^{\prime}=0.72\right)$, which is located upstream of this region at approximately $200 \mathrm{~kb}$.

Two other regions of the large intron 8 (around 800 kb long) display clustering of associated SNPs with HDL or TG. The global haplotypic analyses for these two regions were not significant, indicating that the observed associations in the genotypic analysis seem to be related with individual polymorphic effects rather than to haplotypic blocks.

Genotype imputation methods are now being commonly used in the analysis of genome-wide association studies. Imputation enables researchers to pool and/or compare data between studies conducted using different SNP sets. It is also possible to fine map associated regions. Imputation methods work by combining a reference panel of individuals genotyped at a dense set of polymorphisms with a study sample collected from a genetically similar population and genotyped at a subset of these SNPs. Usually, HapMap panels are employed as the reference sample. It has raised the question about how well these panels represent the genetic variation in other populations that, for historical and demographic reasons, are more distant from the reference population. Two recent papers have analyzed the genomic diversity in European populations and revealed that the level of genetic differentiation within Europe is small [35] while the complex origin of the Spanish population is reflected in a greater haplotypic diversity than Northern/Western Europeans, although this divergence is not statistically significant [36]. These reports are in accordance with our observation that the Spanish population is largely homogeneous and in general similar, to the CEU HapMap sample in terms of MAF and LD patterns, notwithstanding that our population has more blocks and smaller on average [37]. Specifically at the $W W O X$ region, no significant differences were observed between the Spanish and the CEU HapMap sample (Additional files 1-2). Regarding accuracy of imputation, we have recently imputed the complete genome using the $250 \mathrm{k}$ NspI chip information and CEU HapMap sample with an overall concordance of $96.7 \%$ between the genotyped and imputed genotypes revealed by the use of the mask function. These findings are in accordance with the results presented by Huang et al. [38] that described high imputation accuracy for all the European populations examined (including a Spanish sample) with the CEU HapMap reference panel. Another supporting argument for the validity of the imputed genotypes is that the proportion of genotyped:imputed SNPs is 1:6. The associated SNPs are an admixture of both of them in approximately the same proportion: 1:8.7 for HDL, 1:6.6 for TGs and 1:8.4 for TG/HDL, with $\mathrm{p}$ values greater than 0.5 for the comparison of the distribution of associated/not associated SNPs in both genotyped and imputed classes.

In our study, we failed to replicate the association of the rs2548861 with HDL. This polymorphism has been imputed in our study population, and inaccurate imputation could be the cause for the absence of association, although it is unlikely for the reasons exposed above. We have estimated the effect size (ES) of this SNP in our study using the same method employed by Lee based on the $t$ statistics $(E S=\mathrm{t} \times \operatorname{sqrt}[[\mathrm{n} 0+\mathrm{n} 1] /[\mathrm{n} 0 \times \mathrm{n} 1]], \mathrm{ni}=$ number of participants coded as $i$ ), that represents the proportion of one-standard-deviation change in HDL. In our study population, the ES for the rs 2548861 is -0.08 , exactly the same raw score obtained by Lee et al. for the METSIM cohort, which includes more than 4,000 males. We estimate that our study is underpowered for SNPs with effect sizes below 0.14 , so we can not rule out power issues. However, in the report by Lee et al [16] the effect of the rs2548861 was identified in familial cases of dyslipidemia and validated in two large population-based samples of Finnish samples, but the authors also failed to replicate this association in three GWAS dataset: the Diabetes Genetics Initiative (DGI) (1,464 cases of type 2 diabetes and 1,467 non-diabetic control individuals from Scandinavia), the Finland-United States Investigation of NIDDM Genetics (FUSION, 1,161 Finnish type 2 diabetes cases, 1,174 normal glucose tolerant controls, and 122 offspring of case/control pairs) and the Sardinia study of agingassociated variables cohorts (4,305 related individuals). Lee et al. pointed out that part of the initial linkage signal remains unexplained by rs2548861, suggesting that additional variants in the WWOX region influence lipid levels. In fact, the rs 2667590 polymorphism, located also in the intron 8 but not linked to the rs 2548861 polymorphism, has been also associated with HDL levels [12].

In our study, a new region in the WWOX gene, the promoter, is shown to be associated with both HDL and TG levels, spanning the susceptibility region to the proximal region of the long arm of chromosome 16. $10 \mathrm{Mbp}$ away from the WWOX gene, at 16q22, several recent reports have identified different polymorphisms at the lecithincholesterol acyltransferase (LCAT) gene in association 
with HDL [12-15]. It has been recently reported the existence of synthetic associations, that is, combinations of several low frequency variants across large regions of the genome. These synthetic associations can span up to 10 $\mathrm{Mb}$ and encompass several LD blocks [39,40]. It is then possible that the WWOX and the $L C A T$ regions are components of the same synthetic haplotype which contributes to the regulation of blood lipid levels.

The work presented in this article, has identified new putative SNPs associated, not only with HDL, but also with triglycerides and the TG/HDL index, a powerful estimator or cardiovascular risk. In addition to the previously described intron 8 , we have identified the promoter region as a new region influencing both HDL and TG levels. We cannot rule out that some of the observed associations could have arisen by chance, reason why additional, independent replications are needed.

\section{Conclusions}

In conclusion, the information derived from the genome wide genotyping combined with that provided for the imputation procedure, has allowed us to fine map the WWOX region. We agree with Lee et al. [16] on the relevance of $W W O X$ intron 8 in $\mathrm{HDL}$ and we extend it to TG levels. In addition, we have identified the 5' region of the gene as another putative source of HDL and TG variance at least in this Spanish sample. The WWOX gene is therefore a promising target for future research in cardiovascular diseases and risk factors.

\section{Additional material}

Additional file 1: Figure S1: LD map of WWOX gene in the Spanish
population
Additional file 2: Figure S2: LD map of WWOX gene in the CEU
HapMap reference panel
Additional file 3: Table S1: Quality metrics for imputed SNPs
Additional file 4: Figure S3: LD map at WWOX region 1 (Chr.16:
76,689,775-76,716,533 bp)
Additional file 5: Figure S4: LD map at WWOX region 2 (Chr.16:
77,433.428-77,441.867 bp)
Additional file 6: Figure S5: LD map at WWOX region 3 (Chr.16:
77,538.855-77,563.088 bp)
Additional file 7: Figure S6: LD map at WWOX region 4 (Chr.16:
77,605.536-77,620.657 bp)
Additional file 8: Table S2: Association analysis of the WWOX gene
markers with HDL
Additional file 9: Table S3: Association analysis of the WWOX gene
markers with triglycerides
Additional file 10: Table S4: Association analysis of the WWOX gene
markers with TG/HDL index

\section{Acknowledgements}

We thank patients involved in this study. We are deeply grateful to Mari Carmen Rivero, Juan Velasco and Ana Salinas for their technical work.
This work has been supported by grants 830882 from the Consejería de Innovación y Ciencia (Junta de Andalucía), PCT-A41502790-2006/2007 from the Ministerio de Educación y Ciencia and 07/124 from the Corporación Tecnológica de Andalucía (CTA). This work has been also supported by CIBER de Diabetes y Enfermedades Metabólicas Asociadas (CIBERDEM); CIBERDEM is an ISCIII Project.

\section{Author details}

${ }^{1}$ Departamento de Genómica Estructural. Neocodex. C/. Charles Darwin 6, Acc. A, 41092 Sevilla, Spain. Departamento de Medicina Interna II. Hospital Clínico Universitario San Carlos. CIBER de Diabetes y Enfermedades Metabólicas Asociadas (CIBERDEM). C/Profesor Martín Lagos s/n, 28040, Madrid, Spain.

\section{Authors' contributions}

MES: analysed and interpreted data and draft the manuscript.

$A G P, J G$ and AR: have contributed to conception and design of the study and revised the manuscript.

LMR, MTML and MSR: have contributed to the acquisition and interpretation of data and revised the manuscript.

All authors have read and approved the manuscript.

\section{Competing interests}

The authors declare that they have no competing interests.

Received: 4 February 2010 Accepted: 14 October 2010

Published: 14 October 2010

\section{References}

1. Teran-Garcia M, Bouchard C: Genetics of the metabolic syndrome. Applied physiology, nutrition, and metabolism = Physiologie appliquee, nutrition et metabolisme 2007, 32(1):89-114.

2. Kaess B, Fischer M, Baessler A, Stark K, Huber F, Kremer W, Kalbitzer HR, Schunkert $H$, Riegger $G$, Hengstenberg $C$ : The lipoprotein subfraction profile: heritability and identification of quantitative trait loci. Journal of lipid research 2008, 49(4):715-723.

3. Clee SM, Zwinderman AH, Engert JC, Zwarts KY, Molhuizen HO, Roomp K, Jukema JW, van Wijland M, van Dam M, Hudson TJ, et al: Common genetic variation in $A B C A 1$ is associated with altered lipoprotein levels and a modified risk for coronary artery disease. Circulation 2001, 103(9):1198-1205.

4. Humphries S, Coviello DA, Masturzo P, Balestreri R, Orecchini G, Bertolini S: Variation in the low density lipoprotein receptor gene is associated with differences in plasma low density lipoprotein cholesterol levels in young and old normal individuals from Italy. Arterioscler Thromb 1991, 11(3):509-516.

5. Lehtimaki T, Moilanen T, Aalto-Setala K, Kontula K, Porkka K, Akerblom HK, Ehnholm C, Ronnemaa T, Viikari J: Association of apolipoprotein E and B polymorphisms with serum lipids. Annals of medicine 1991, 23(6):657-662.

6. Pihlajamaki J, Karjalainen L, Karhapaa P, Vauhkonen I, Taskinen MR, Deeb SS, Laakso M: G-250A substitution in promoter of hepatic lipase gene is associated with dyslipidemia and insulin resistance in healthy control subjects and in members of families with familial combined hyperlipidemia. Arteriosclerosis, thrombosis, and vascular biology 2000, 20(7):1789-1795.

7. Razzaghi H, Aston CE, Hamman RF, Kamboh Ml: Genetic screening of the lipoprotein lipase gene for mutations associated with high triglyceride/ low HDL-cholesterol levels. Human genetics 2000, 107(3):257-267.

8. Talmud PJ, Hawe E, Martin S, Olivier M, Miller GJ, Rubin EM, Pennacchio LA, Humphries SE: Relative contribution of variation within the APOC3/A4/A5 gene cluster in determining plasma triglycerides. Human molecular genetics 2002, 11(24):3039-3046.

9. Heijmans BT, Beekman M, Putter H, Lakenberg N, van der Wijk HJ, Whitfield JB, Posthuma D, Pedersen NL, Martin NG, Boomsma Dl, et al: Meta-analysis of four new genome scans for lipid parameters and analysis of positional candidates in positive linkage regions. Eur J Hum Genet 2005, 13(10):1143-1153.

10. Klos KL, Sing CF, Boerwinkle E, Hamon SC, Rea TJ, Clark A, Fornage M, Hixson JE: Consistent effects of genes involved in reverse cholesterol transport on plasma lipid and apolipoprotein levels in CARDIA 
participants. Arteriosclerosis, thrombosis, and vascular biology 2006 26(8):1828-1836.

11. Wang X, Paigen B: Genome-wide search for new genes controlling plasma lipid concentrations in mice and humans. Current opinion in lipidology 2005, 16(2):127-137.

12. Willer CJ, Sanna S, Jackson AU, Scuteri A, Bonnycastle LL, Clarke R, Heath SC, Timpson NJ, Najjar SS, Stringham HM, et al: Newly identified loci that influence lipid concentrations and risk of coronary artery disease. Nature genetics 2008, 40(2):161-169.

13. Aulchenko YS, Ripatti S, Lindqvist I, Boomsma D, Heid IM, Pramstaller PP, Penninx BW, Janssens AC, Wilson JF, Spector T, et al: Loci influencing lipid levels and coronary heart disease risk in 16 European population cohorts. Nature genetics 2009, 41(1):47-55.

14. Kathiresan S, Willer CJ, Peloso GM, Demissie S, Musunuru K, Schadt EE, Kaplan L, Bennett D, Li Y, Tanaka T, et al: Common variants at 30 loci contribute to polygenic dyslipidemia. Nature genetics 2009, 41(1):56-65.

15. Sabatti C, Service SK, Hartikainen AL, Pouta A, Ripatti S, Brodsky J, Jones CG, Zaitlen NA, Varilo T, Kaakinen M, et al: Genome-wide association analysis of metabolic traits in a birth cohort from a founder population. Nature genetics 2009, 41(1):35-46.

16. Lee JC, Weissglas-Volkov D, Kyttala M, Dastani Z, Cantor RM, Sobel EM, Plaisier CL, Engert JC, van Greevenbroek MM, Kane JP, et al: WW-domaincontaining oxidoreductase is associated with low plasma HDL-C levels. American journal of human genetics 2008, 83(2):180-192.

17. Dastani Z, Quiogue L, Plaisier C, Engert JC, Marcil M, Genest J, Pajukanta P: Evidence for a gene influencing high-density lipoprotein cholesterol on chromosome 4q31.21. Arteriosclerosis, thrombosis, and vascular biology 2006, 26(2):392-397.

18. Mahaney MC, Almasy L, Rainwater DL, VandeBerg JL, Cole SA, Hixson JE, Blangero J, MacCluer JW: A quantitative trait locus on chromosome 16q influences variation in plasma $\mathrm{HDL}-\mathrm{C}$ levels in Mexican Americans. Arteriosclerosis, thrombosis, and vascular biology 2003, 23(2):339-345.

19. Pajukanta P, Allayee H, Krass KL, Kuraishy A, Soro A, Lilja HE, Mar R, Taskinen MR, Nuotio I, Laakso M, et al: Combined analysis of genome scans of dutch and finnish families reveals a susceptibility locus for high-density lipoprotein cholesterol on chromosome 16q. American journal of human genetics 2003, 72(4):903-917.

20. Shearman AM, Ordovas JM, Cupples LA, Schaefer EJ, Harmon MD, Shao Y, Keen JD, DeStefano AL, Joost O, Wilson PW, et al: Evidence for a gene influencing the TG/HDL-C ratio on chromosome 7q32.3-qter: a genomewide scan in the Framingham study. Human molecular genetics 2000, 9(9):1315-1320.

21. Soro A, Pajukanta P, Lilja HE, Ylitalo K, Hiekkalinna T, Perola M, Cantor RM, Viikari JS, Taskinen MR, Peltonen L: Genome scans provide evidence for low-HDL-C loci on chromosomes 8q23, 16q24.1-24.2, and 20q13.11 in Finnish families. American journal of human genetics 2002, 70(5):1333-1340.

22. Nunez MI, Ludes-Meyers J, Aldaz CM: WWOX protein expression in normal human tissues. J Mol Histol 2006, 37(3-4):115-125.

23. Aqeilan $\mathrm{Rl}$, Croce CM: WWOX in biological control and tumorigenesis. Journal of cellular physiology 2007, 212(2):307-310.

24. Bednarek AK, Keck-Waggoner CL, Daniel RL, Laflin KJ, Bergsagel PL, Kiguchi K, Brenner AJ, Aldaz CM: WWOX, the FRA16D gene, behaves as a suppressor of tumor growth. Cancer research 2001, 61(22):8068-8073.

25. Paige AJ, Taylor KJ, Taylor C, Hillier SG, Farrington S, Scott D, Porteous DJ, Smyth JF, Gabra H, Watson JE: WWOX: a candidate tumor suppressor gene involved in multiple tumor types. Proceedings of the National Academy of Sciences of the United States of America 2001, 98(20):11417-11422.

26. Aqeilan RI, Hassan MQ, de Bruin A, Hagan JP, Volinia S, Palumbo T, Hussain S, Lee SH, Gaur T, Stein GS, et al: The WwOX tumor suppressor is essential for postnatal survival and normal bone metabolism. The Journal of biological chemistry 2008, 283(31):21629-21639.

27. Vasan RS, Glazer NL, Felix JF, Lieb W, Wild PS, Felix SB, Watzinger N, Larson MG, Smith NL, Dehghan A, et al: Genetic variants associated with cardiac structure and function: a meta-analysis and replication of genome-wide association data. JAMA 2009, 302(2):168-178.

28. Burchfiel CM, Laws A, Benfante R, Goldberg RJ, Hwang LJ, Chiu D, Rodriguez BL, Curb JD, Sharp DS: Combined effects of HDL cholesterol, triglyceride, and total cholesterol concentrations on 18-year risk of atherosclerotic disease. Circulation 1995, 92(6):1430-1436.
29. Li Y, Abecasis GR: Mach 1.0: Rapid haplotype reconstruction and missing genotype inference. American journal of human genetics 2006, S79:2290.

30. Lorenzo C, Serrano-Rios M, Martinez-Larrad MT, Gabriel R, Williams K, Gonzalez-Villalpando C, Stern MP, Hazuda HP, Haffner SM: Was the historic contribution of Spain to the Mexican gene pool partially responsible for the higher prevalence of type 2 diabetes in mexican-origin populations? The Spanish Insulin Resistance Study Group, the San Antonio Heart Study, and the Mexico City Diabetes Study. Diabetes care 2001, 24(12):2059-2064.

31. Martinez-Larrad MT, Fernandez-Perez C, Gonzalez-Sanchez UL, Lopez A, Fernandez-Alvarez J, Riviriego J, Serrano-Rios M: [Prevalence of the metabolic syndrome (ATP-III criteria). Population-based study of rural and urban areas in the Spanish province of Segovia]. Medicina clinica 2005, 125(13):481-486.

32. Purcell $S$, Neale B, Todd-Brown $K$, Thomas $L$, Ferreira MA, Bender D, Maller J, Sklar P, de Bakker PI, Daly MJ, et al: PLINK: a tool set for whole-genome association and population-based linkage analyses. American journal of human genetics 2007, 81(3):559-575.

33. Barrett JC, Fry B, Maller J, Daly MJ: Haploview: analysis and visualization of LD and haplotype maps. Bioinformatics 2005, 21(2):263-265.

34. Del Mare S, Salah Z, Aqeilan Rl: WWOX: Its genomics, partners, and functions. Journal of cellular biochemistry 2009, 108(4):737-745.

35. Novembre J, Johnson T, Bryc K, Kutalik Z, Boyko AR, Auton A, Indap A, King KS, Bergmann S, Nelson MR, et al: Genes mirror geography within Europe. Nature 2008, 456(7218):98-101.

36. Auton A, Bryc K, Boyko AR, Lohmueller KE, Novembre J, Reynolds A, Indap A, Wright MH, Degenhardt JD, Gutenkunst RN, et al: Global distribution of genomic diversity underscores rich complex history of continental human populations. Genome research 2009, 19(5):795-803.

37. Gayan J, Galan JJ, Gonzalez-Perez A, Saez ME, Martinez-Larrad MT, Zabena C, Rivero MC, Salinas A, Ramirez-Lorca R, Moron FJ, et al: Genetic Structure of the Spanish Population. BMC Genomics 11(1):326.

38. Huang $L, L i Y$, Singleton $A B$, Hardy JA, Abecasis G, Rosenberg NA, Scheet P: Genotype-imputation accuracy across worldwide human populations. American journal of human genetics 2009, 84(2):235-250.

39. Dickson SP, Wang K, Krantz I, Hakonarson H, Goldstein DB: Rare variants create synthetic genome-wide associations. PLOS biology 8(1):e1000294.

40. Fellay J, Thompson AJ, Ge D, Gumbs CE, Urban TJ, Shianna KV, Little LD, Qiu P, Bertelsen AH, Watson $M$, et al: ITPA gene variants protect against anaemia in patients treated for chronic hepatitis C. Nature 464(7287):405-408

\section{Pre-publication history}

The pre-publication history for this paper can be accessed here: http://www.biomedcentral.com/1471-2350/11/148/prepub

\section{doi:10.1186/1471-2350-11-148}

Cite this article as: Sáez et al:: WWOX gene is associated with HDL cholesterol and triglyceride levels. BMC Medical Genetics 2010 11:148.

\section{Submit your next manuscript to BioMed Central and take full advantage of:}

- Convenient online submission

- Thorough peer review

- No space constraints or color figure charges

- Immediate publication on acceptance

- Inclusion in PubMed, CAS, Scopus and Google Scholar

- Research which is freely available for redistribution

Submit your manuscript at www.biomedcentral.com/submit
C Biomed Central 